\title{
E-Learning by Using Content Management System (CMS)
}

\author{
Reem Razzaq Abdul Hussein ${ }^{1}$ \\ Iraqi Commission for Computer \\ and Informatics Informatics \\ Baghdad, Iraq
}

\author{
Afaf Badie Al-Kaddo ${ }^{2}$ \\ Dept. of Computer Science \\ University of Baghdad \\ College of Education for Women \\ Baghdad, Iraq
}

\begin{abstract}
Content Management System (CMS) is a system to manage content in order to improve the educational process and to create an interactive environment where the content management system plays a role in e-learning. CMS software named (joomla) contains sources of commercial extension, the contribution of the proposed paper is replacing the commercial by a range of free extension application and employed them in the field of e-learning where new features are added to the program do not exist in the original version of joomla. The paper took advantage of these new features in building a system used by lecturers to develop the skills and capabilities of students through the electronic portal and to raise the educational level of them.
\end{abstract}

Keywords-E-learning; Content Management Systems; Joomla; Lecturer; Student

\section{INTRODUCTION}

E-learning becoming an important part in the universities, institutes and organizations learning management system. Some educational centers are using e-learning to enhance their traditional learning system while other have created alternative model based on virtual learning and are using elearning as a new learning method[1].

The term "e-learning" has many definitions, a definition by Rosenberg, "the first and most important feature of elearning is that it takes place in a networked environment". This means that computer of the learner is in constant communication with a central server. Also e-learning materials are accessible via an internet browser on a personal computer [2]. The goal of the proposed paper is to demonstrate that the proposed management system helps in digital learning. The paper is organized as follow: Section two explains the content management and content management system, section three explains the requirements of education, section four explains assessment of e-learning, section five explains the software used in the proposed system, section six explains the tools of the proposed system finally conclusion and future work.

\section{Content MANAgEMENT AND Content MANAGEMENT SYSTEM}

Content is not a single piece of information, but a conglomeration of pieces of information put together to form a cohesive whole.
Due to the exponential growth of information, the task of finding information becomes like finding an expensive thing in deep water. Therefore, content becomes the backbone for any organization, every interaction that occurs through the entire range of organizational activity.

Content are stored, retrieved, modified, updated, and controlled, then put the output in a different ways that the incremental cost in each update and production decreases over time. There are a number of challenges and issues concerned with CMS [3].

LMS Learning Management Systems (LMS) such as Moodle (Modular Object-Oriented Dynamic Learning Environment) is basically an Open Source e-learning platform. Moodle is a Course Management System (CMS) - a software package designed to help educators to create quality online courses [4]. Joomla generates a generic website, generally of a forum but can also be styled to be many other types of site. Basically it can be made to do anything. Moodle however is specifically oriented towards the provision of educational material. These CMSs are also called Learning Management Systems (LMS) or a Virtual Learning Environment (VLE). So it comes with the components and modules ready for this type of use.

In the IT (Information Technology) context, Content Management System (CMS) is a system that facilitates the creation, retrieval and editing of information/knowledge in digital fashion including semi or fully processed content like images/graphics/animation, audio/video, etc., in real time or as needed. CMS is a system that manages content. CMS range from very simple databases to complex applications. The more complex systems can be integrated with the digital resources to enable access to digital assets and to allow regular updating [3]. The proposed paper used software named joomla for this purpose to provide a large number of services and modules which can be easily installed, configured and modify that closely match the objective of the proposed paper. Joomla is based on PHP scripting language and implements MVC (Model-View-Controller) framework, joomla preferably uses MySQL database software for storing data. Furthermore Joomla has a back-end where the administrator of the website can create, update and delete any data [5].

\section{THE REQUIREMENTS OF EDUCATION}

The requirements of education need the following: 


\section{A. Courseware Creation, Retrieval and Updating}

Handling research or patent related information. Also the education needs to interactive retrieval, real time content exchange, multimedia provisioning, etc.

\section{B. Transform the Content}

For presentation over different devices including handheld and other portable or mobile communication devices.

\section{On-line Publishing}

It indicates the activities such as evolution of a learning architecture in terms of change management and reinventing the conventional training organization apart from other issues. The transition from old to new framework of learning can be noted in Fig. 1.

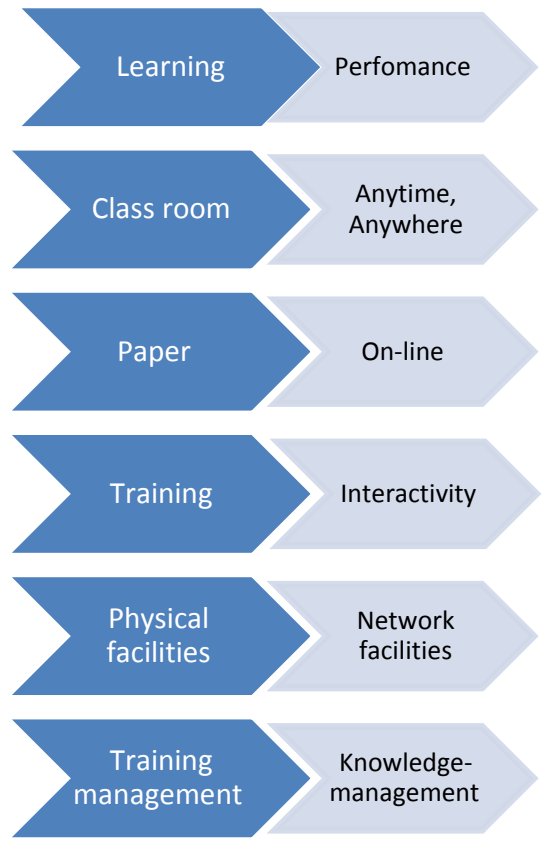

Fig. 1. The Transition from Old to New Framework of Learning

\section{ASSESSMENT OF E-LEARNING AND PROVISION OF FEEDBACK}

Assessment and feedback lies at the heart of the learning experience, and forms a significant part of both academic and administrative workload. It remains the biggest source of student dissatisfaction with the higher education experience. The providers of higher education are seeking to improve their approaches to better meet learner needs and expectations in the face of increasing resource constraints [7].

Communication of formative feedback is very important since the method selected may discourage or draw students' attention in the feedback process.

Communication of formative feedback should ensure that students engage with the content provided. Students can be communicated with formative feedback by traditional and electronic ways. Traditional includes handwritten comments and print-outs of word-processed feedback forms which are returned back to the students. Traditional communications are not efficient because they have a problem of not reaching the student. Electronic feedback methods such as emailing comments to students as a simple technique to more complex tools such as place comments and notes by tutors to electronically that allow tutors to place comments and annotations to electronically work. The latest methods are used by teachers because they improve feedback production, communication and delivery [7].

\section{THE SOFTware USEd IN THE Proposed System}

The technology used for creating e-learning platform is Content Management System (CMS) software named JoomlaVer. 2.5.17. In the proposed system many free software are grouped together and installed inside CMS to serve educational web site (instead of commercial). These free installed software are shown in table 1. By using the new extensions, new features of e-learning will be added to joomla in addition to displaying the contents.

TABLE I. FREE INSTALLED SOFTWARE INSIDE JOOMLA

\begin{tabular}{|c|l|l|}
\hline Version & Type & $\begin{array}{l}\text { Free Software } \\
\text { Name }\end{array}$ \\
\hline V. 2.5.17 & $\begin{array}{l}\text { Content } \\
\text { Management } \\
\text { System }\end{array}$ & Joomla \\
\hline V. 1.2.3 & component & ARI.QuzieLite \\
\hline V. 1.6.1 & component & Discussions \\
\hline V .3.0.9 & component & Fabrik \\
\hline V. 7 & Module & Freichat \\
\hline V. 1.0 & Module & $\begin{array}{l}\text { Easy Folder } \\
\text { Listing }\end{array}$ \\
\hline
\end{tabular}

\section{THE TOOLS OF THE PROPOSED SYSTEM}

E- Learning provides an opportunity for education and training. E- Learning does not need to commit to the time, place of the lecture and the duration of the semester. For this reason, e-learning provides flexibility. The proposed system is based on the internet and used CMS, collaborative, management, courses, authorization and evaluation, and assessment tools as shown in Fig. 2.

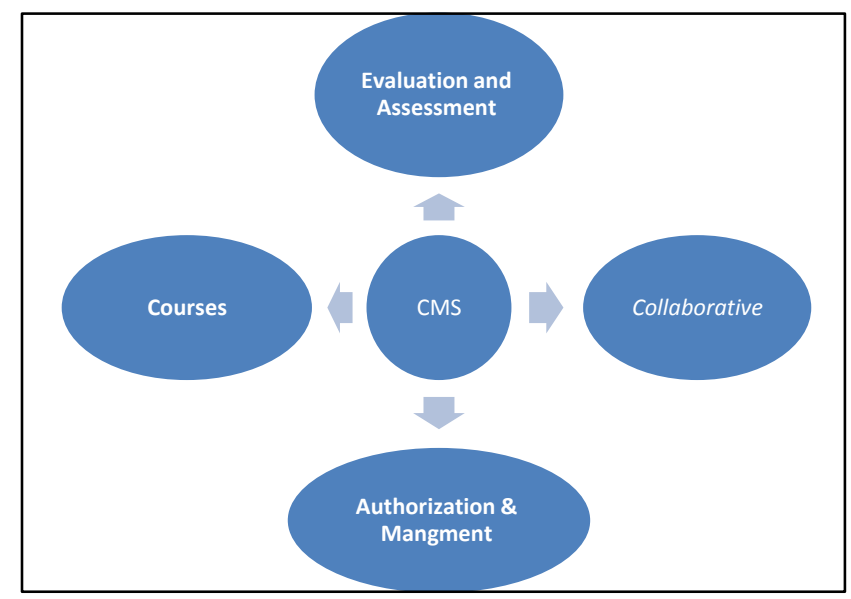

Fig. 2. Tools of the Proposed System 


\section{1) $C M S$}

A Content Management System is a collection of procedures used to describe processes in an environment that requires collaboration between different actors. Content Management System is basically designed to support educative or academic courses. It allows the instructor to create a course website, where documents can be uploaded in popular formats such as word, power point, etc.

\section{2) Evaluation and Assessment}

Assessment is used to identify what student knows, student's performance and needs. The basic advantages of the assessment are: reduces the effort, time, and improve reliability (avoiding human errors). In the proposed system the ARI.QuzieLite component had been installed into joomla to create various tests to evaluate respondent's level of knowledge. The ARI.QuzieLite component also allows grouping tests via categories by providing three different types of tests. The first type is multiple choices test as shown in Fig. 3, the second test is a text as shown in Fig. 4, and the last test is yes/no answer as shown in Fig. 5.

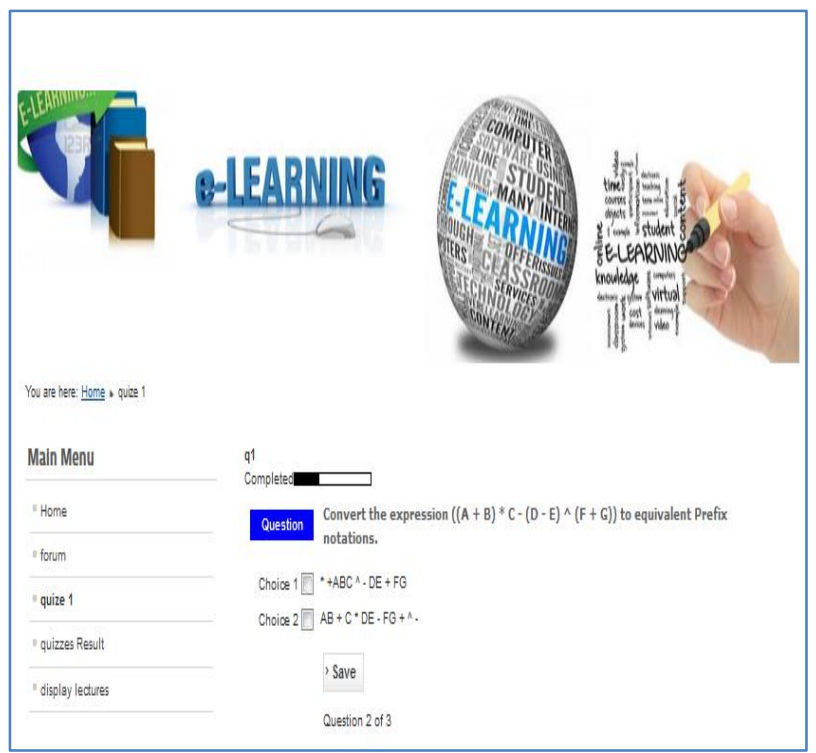

Fig. 3. Snap Shot of Multiple Choices

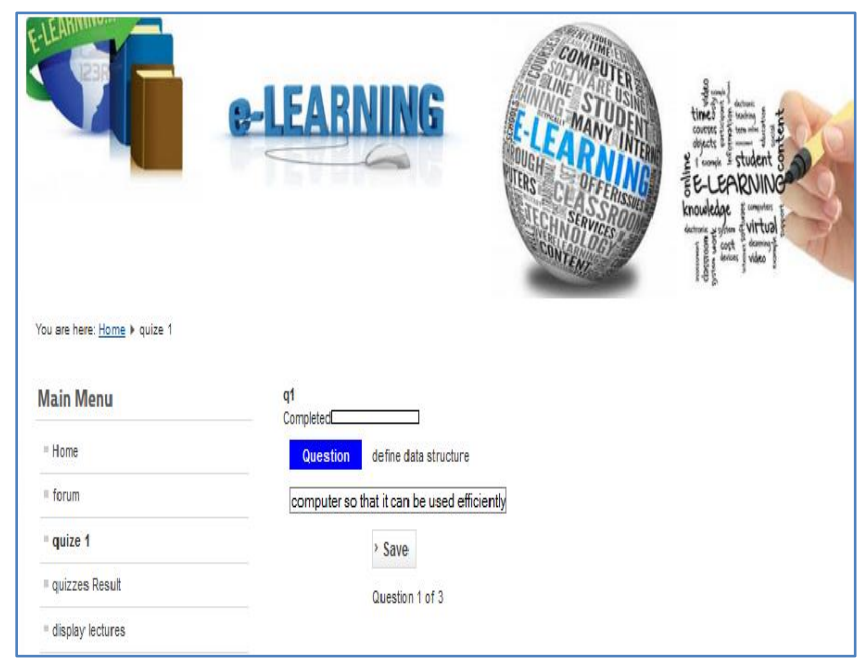

Fig. 4. Snap Shot of a text

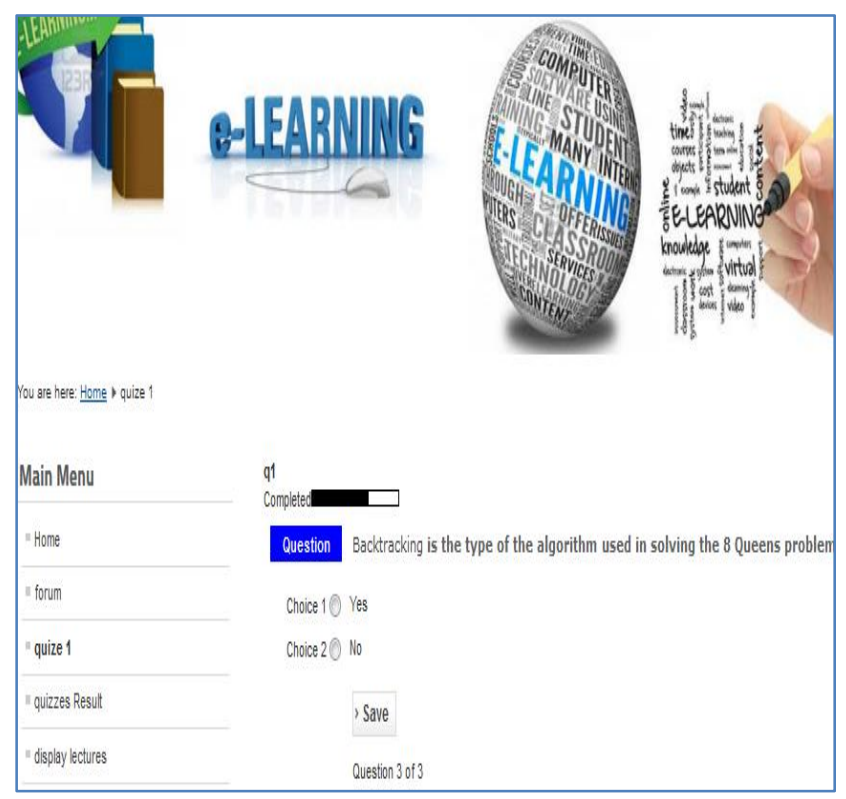

Fig. 5. Snap Shot of (yes/no) Answer 
The Result of the test can be printed and e-mailed as shown in Fig. 6.

Also by using ARI.QuzieLite component student's name, exporting the result to CSV ( Comma Separated Values) and selecting number of questions randomly or in queue can be done as shown in Fig. 7.

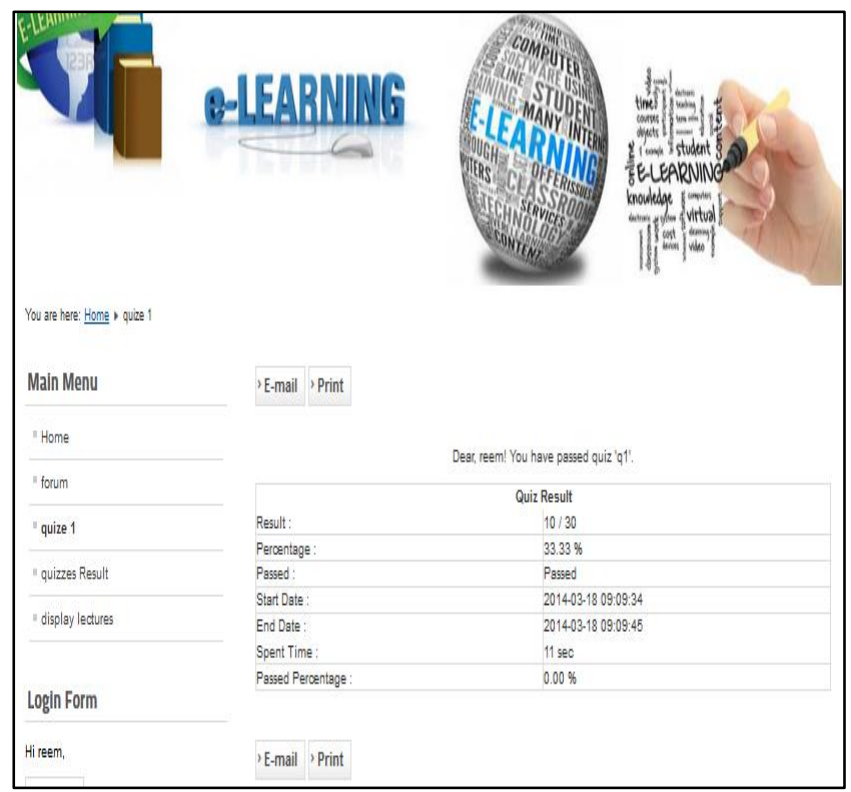

Fig. 6. Snap Shot of the Test Result

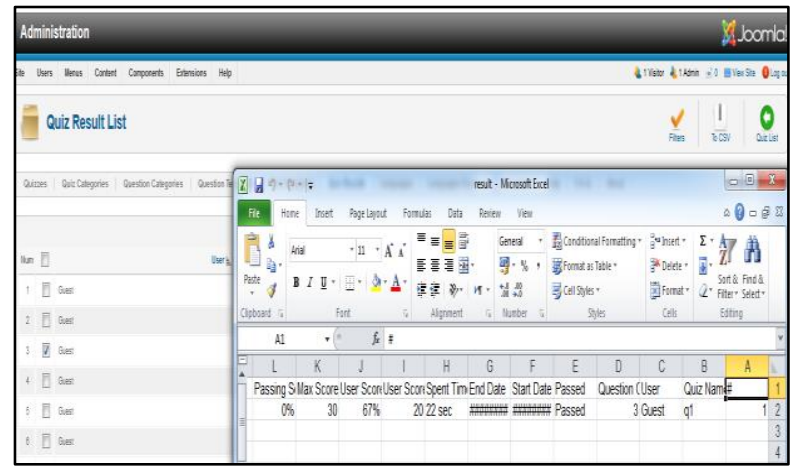

Fig. 7. Export the Result to CSV

\section{3) Collaborative}

Collaborative is used to create collaborative environment through discussions and knowledge-sharing to work together on a common project/ subject online by using chats, email and discussion forums. The role of the student is not confined to access the courseware but to participate, comment and give an opinion. The lecturer directs students, determines the curriculum and uses appropriate manner to facilitate students' understanding. The collaborative environments include:

\section{a) Chat}

Most of the students are already familiar with chat and can generate ideas which may not arise during a classroom discussion. The proposed system installed free web-based chat program FreiChat component for website. FreiChat automatically integrates with joomla site's login which includes friends list and set status updates (such as available, busy, offline and invisible) as shown in Fig. 8 and Chat rooms feature is shown in Fig. 9.

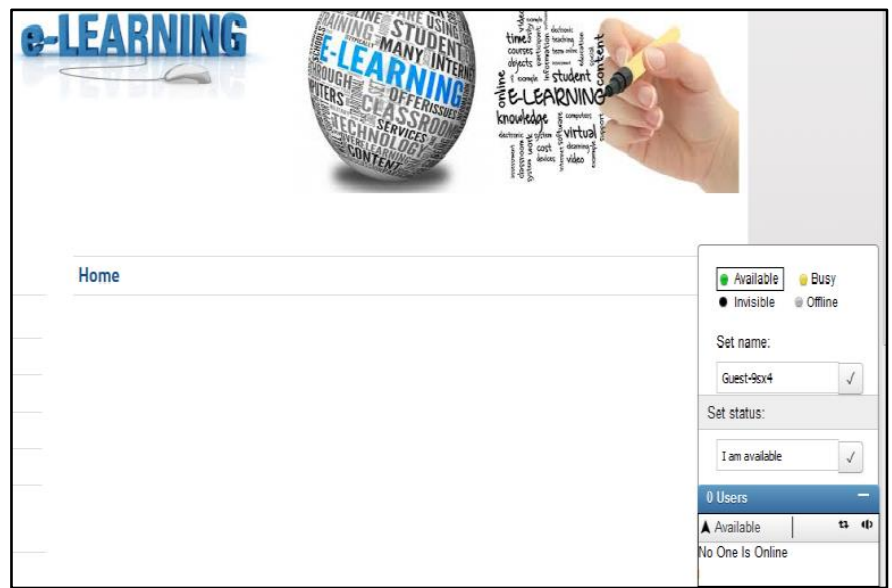

Fig. 8. Chat Options

\begin{tabular}{|c|c|}
\hline & Hide \\
\hline & Powered By Codologic \\
\hline Fun Talk & 1 online \\
\hline Think out loud & 0 online \\
\hline Talk to me & 0 online \\
\hline Talk innovative & 0 online \\
\hline Crazy chat & 0 online \\
\hline
\end{tabular}

Fig. 9. Chat Room

\section{b) E-mail}

In this option, ability to send conversation as e-mail, save chat history, smiley, able to chat even while user browse different pages and option for username or nickname are available.

\section{c) Forum}

Lecturers and Students have the freedom to continue dialogues about the subjects that need discussion regardless of time and length of the subject, and enhancing communications between lecturers and students. The lecturers or students can enter into forum through main menu which is used to make discussion between them. The proposed system installed discussions component of joomla which includes built-in messaging as shown in Fig. 10. Discussion component consists of three parts: forum, profile and mailbox as shown in Figs. 11, 12 and 13. 


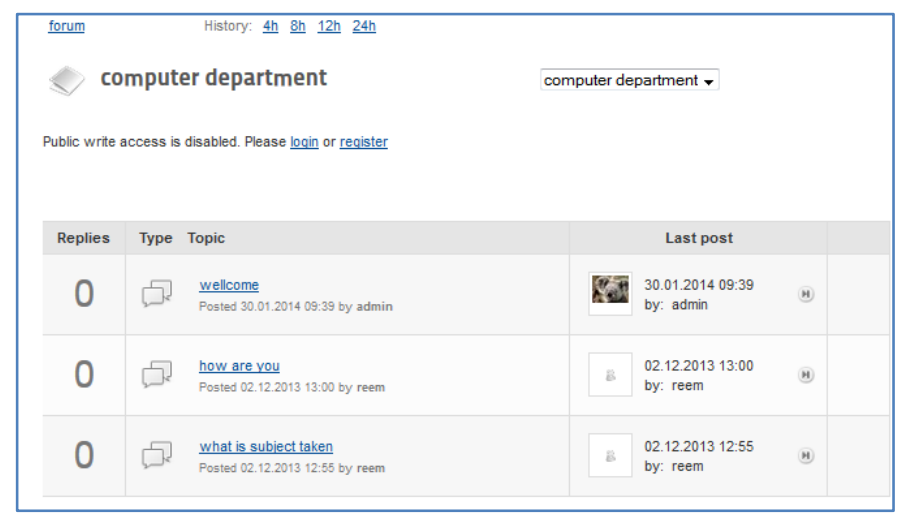

Fig. 10. Parts of Discussion Component

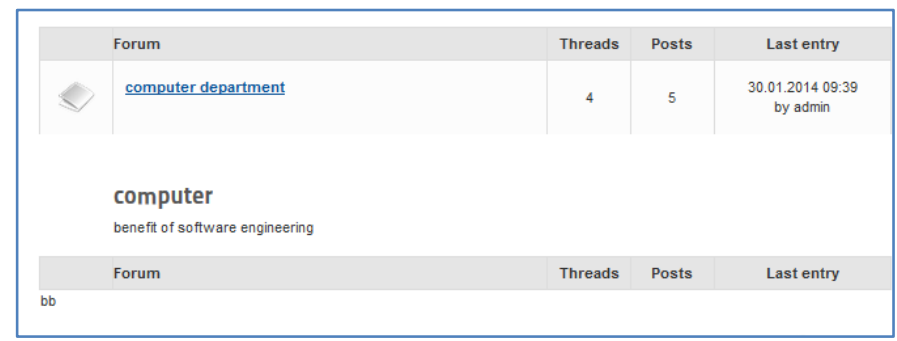

Fig. 11. Forum Part

The user profile part includes city, country, Twitter, Facebook, Google+, Flicker, avatar, ability to add signature as a text, website of the user, image upload and ability to upload YouTube videos in forum as shown in Fig. 12.

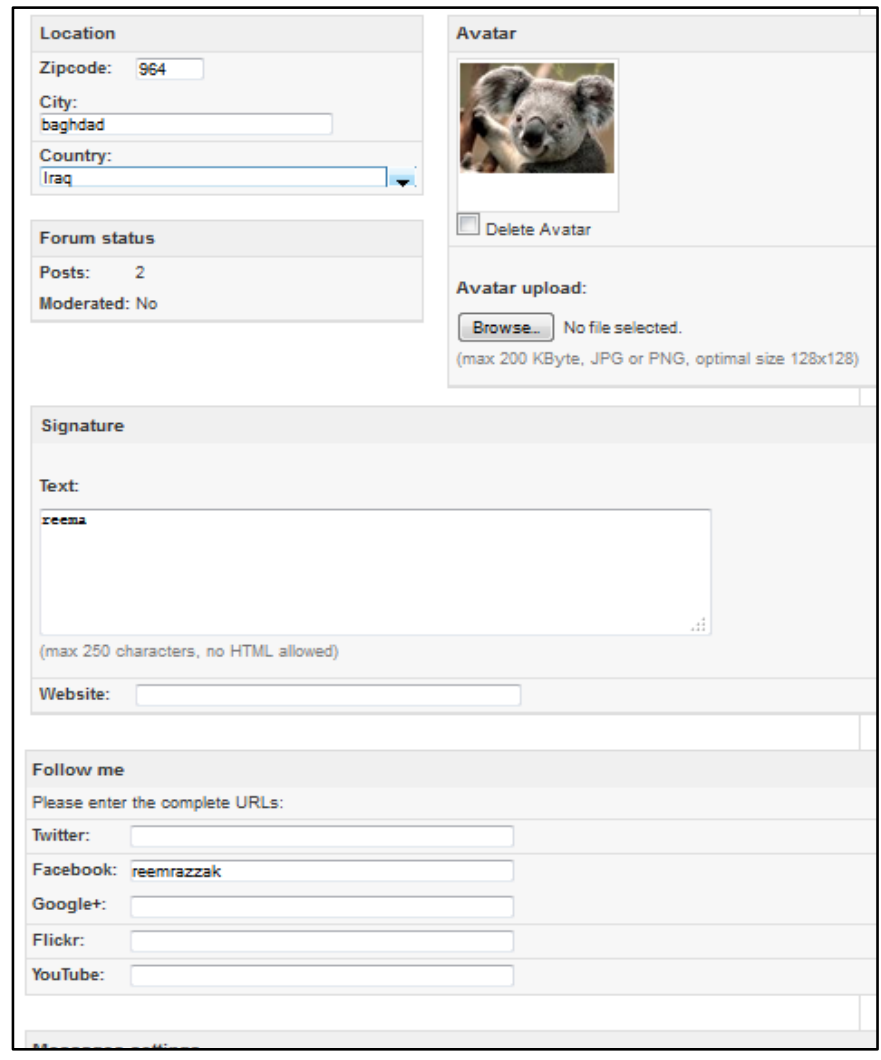

Fig. 12. User Profile Part
In mail box part, post messages are an effective way of communicating feedback to students. E-mail is also used to solve the problem of reaching the student, supports individualized feedback, and notifications.

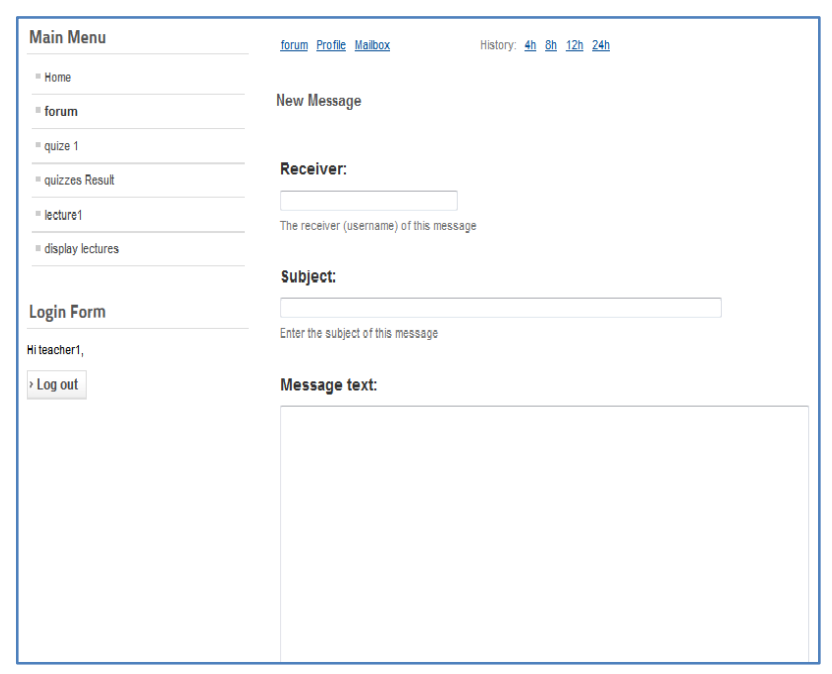

Fig. 13. Mail box Part

The sent messages are stored in an inbox with their details (name of sender, subjects and Date/Time). Select/delete messages are also available in mail box as shown in Fig. 14.

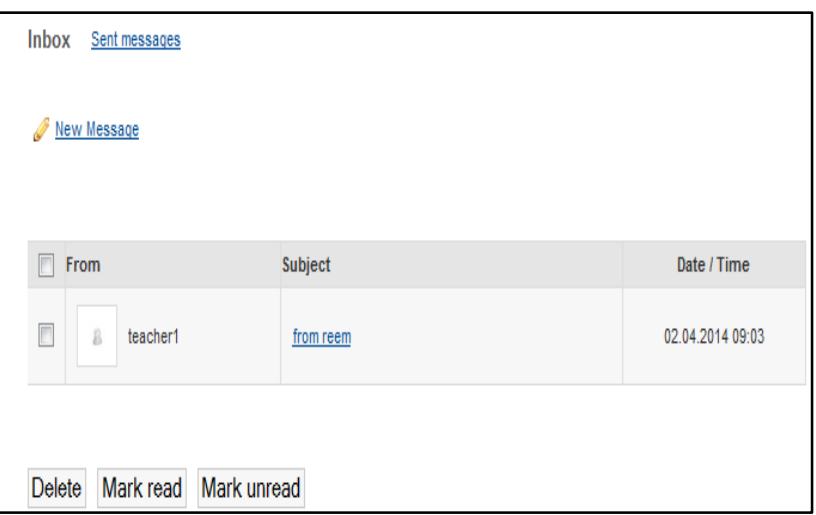

Fig. 14. Sent Messages in an Inbox

\section{4) Authorizing and Management}

The proposed system has three access levels, administrator, lecturer and student. The registration is done after login by using user name and password as shown in Fig. 15.

- Administrator is responsible for managing the whole system.

- Lecturer is responsible for (reading/ writing) lectures.

- Student is responsible for reading lectures. 


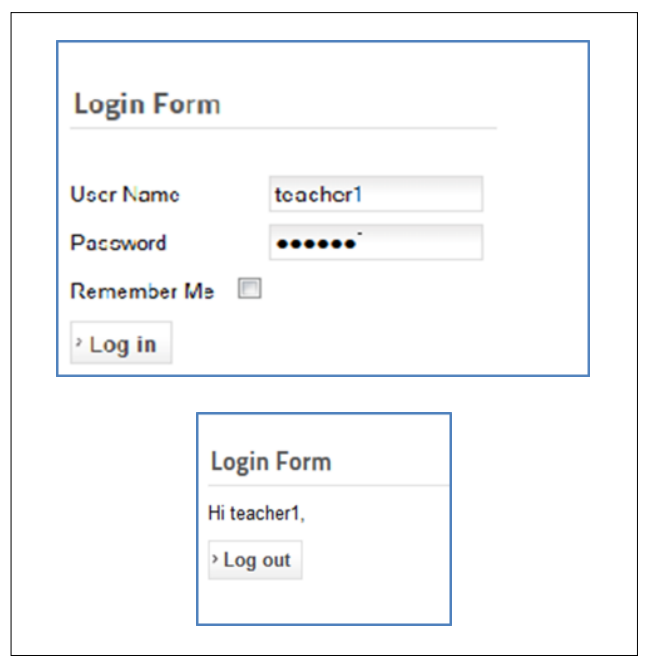

Fig. 15. Registration

\section{5) Courses}

Courses providing $24 / 7$ accessibility to course materials for students. Online lessons include: texts, images and interactions. Courses consist of two parts:

-Upload courses: can be accessed by lecturers only. The proposed system installed fabrik open source Joomla application builder component to give ability to create forms and upload file in different formula (pdf, ppt, img ...). Fig. 16 explains upload courses.

-Download courses: can be accessed by both the lecturers and the students. The proposed system installed module name Easy Folder Listing to display the contents of the folder in formula (pdf, ppt...) as a table or as a list. The folder can display the filename with/without extension, with/without modified date, the size of the file, and an icon representing the type of the file as shown in Fig. 17.

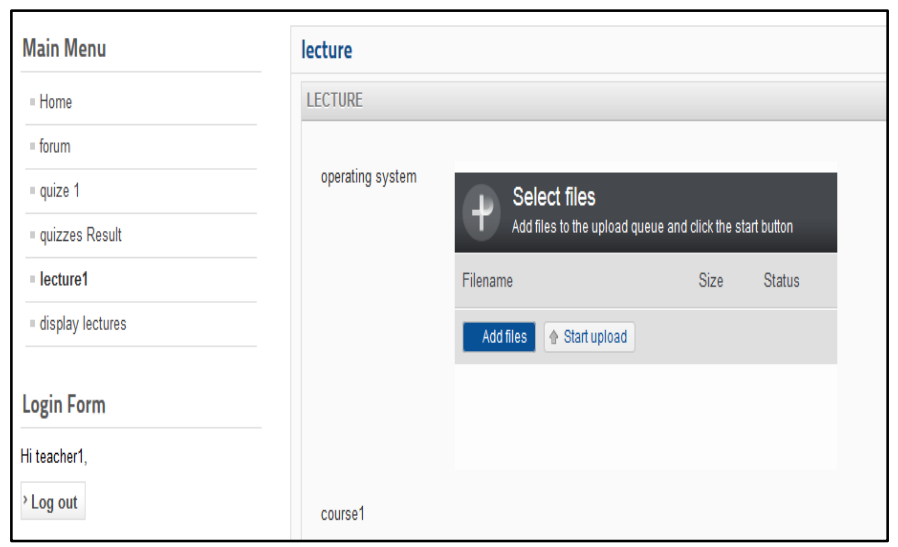

Fig. 16. Upload Courses

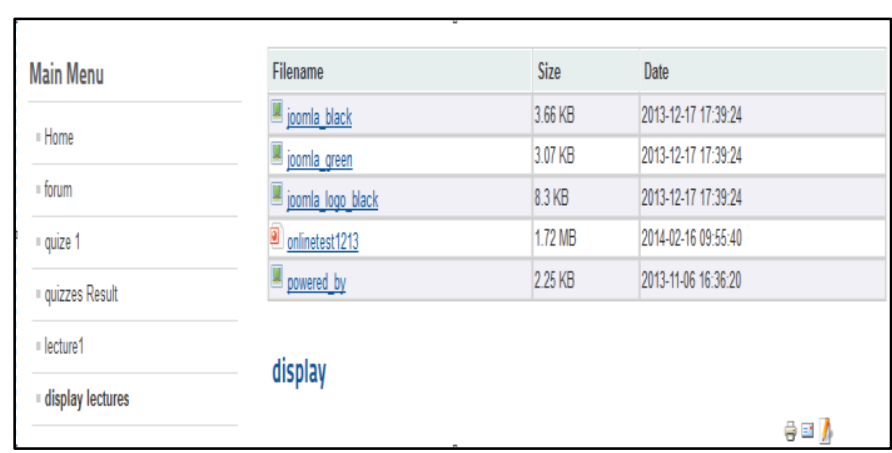

Fig. 17. Download Courses

\section{CONCLUSION}

The proposed paper used Joomla to design a Content Management System (CMS), which enables you to build Web sites and powerful online community management systems. Many aspects, including its ease-of-use and extensibility, have made joomla the most popular Web site software available. Best of all, joomla is an open source solution that is freely available to everyone.

\section{FUTURE WORK}

Joomla content management system are used and many free extensions are added in the proposed paper. We suggest adding wiki pedia to joomla as future work to add more new information to the system.

\section{REFERENCES}

[1] J.A. Itmazi ,M.G.Megias , "Survey: Comparison and Evaluation Studies of learning Content Management Systems", 2004.

[2] Suman Ninoriya, P.M. Chawan, B.B. Meshram, "CMS, LMS and LCMS for E-learning ", International Journal of Computer Science Issues (IJCSI), vol. 8, pp. 644-647, Issue 2, March 2011.

[3] VDebanshuKarmakar, Suman S., " E- Learning Trends of CMS and the Role of Digital Libraries", 2002.

[4] Dharmendra Chourishi, Chanchal Kumar Buttan, Abhishek Chaurasia, Anita Soni, " Effective E-Learning through Moodle", International Journal of Advance Technology \& Engineering Research (IJATER), vol. 1, Issue 1, November 2011.

[5] Amit Ashok Kamble, Jimmi Rosa, Kevin Reynolds, Pablo Matamoros, "Customization of CMS Software for E-Learning Platform Implementation for Dentists", 2012.

[6] G. Ferrell, "A view of the Assessment and Feedback Landscape: Baseline Analysis of Policy and Practice from the JISC Assessment\&Feedback Programme", a report for JISC by Gill Ferrell, April 2012.

[7] H. Thanos, and I. Paraskakis, "Enhancing the Impact of Formative Feedback on Student Learning Through an Online Feedback System", Electronic Journal of E-learning, vol. 8, Issue (111 - 122), 2010. 